\title{
Vertical gradients of lung density in healthy supine
}

\section{men}

\author{
A B MILLAR, D M DENISON
}

From the Lung Function and Computed Tomography Units, Brompton Hospital, London

ABSTRACT Computed tomography was used to determine the vertical gradient of physical density in peripheral lung tissue of 12 healthy supine subjects, at total lung capacity and residual volume. At total lung capacity the mean (SD) density of peripheral lung tissue at the level of the mid right atrium was $0.0715(0.017) \mathrm{g} / \mathrm{cm}^{3}$ and the vertical gradient of density was slight. At residual volume the density of peripheral tissue at the same level was $0.272(0.067) \mathrm{g} / \mathrm{cm}^{3}$ and the vertical density gradient was curvilinear and more pronounced. Predictions of the gradient at residual volume were made on the basis of the known compliance of the lung and measured effects were attributed to the action of gravity on blood vessel distensibility at total lung capacity. These predictions agreed closely with the actual density gradient measured at residual volume and provide a basis for forecasting the vertical density gradient that would exist in healthy lungs at any degree of inflation. Departure from these gradients would imply local abnormalities of lung compliance, distribution of mechanical stress, or distensibility of vessels.

\section{Introduction}

Computed tomograms of comparable sections of lung taken at total lung capacity (TLC) and residual volume (RV) show differences in slice area, mean density, and the vertical distribution of density (fig 1 ). We have previously reported that these changes in area and mean density at different lung volumes may be used to assess regional gas and tissue volume in both normal ${ }^{1}$ and diseased lungs. ${ }^{2}$ Other investigators have commented on the vertical gradient of density, which is barely apparent in computed tomography scans of healthy lungs, taken at full inspiration,,$^{3-7}$ but becomes much more striking in scans taken at full expiration. ${ }^{3-7}$ To study this change in vertical distribution of density further, we quantified the gradient in the peripheral lung tissue of 12 healthy supine men on the basis of tomograms taken at total lung capacity and residual volume and attempted to explain the findings by simple mechanical models. For this, firther information was obtained from the scans of the 12 subjects reported previously.'

\section{Methods}

\section{SUBJECTS}

The subjects had been selected retrospectively from a Address for correspondence: Dr A Millar, Department of Medicine, Jules Thorn Institute, Middlesex Hospital, London WIN 8AA. (Reprints will not be available.)

group of commercial divers with possible pulmonary barotrauma, who had been referred to us for detailed study before they could be given a "fitness to dive" certificate. Each diver had conventional chest radiography, a full set of routine lung function tests, and within 24 hours of the latter computed tomography. The subjects included in the present study had completely normal findings for the lung function tests, conventional posteroanterior radiograph, and computed tomograms. The age, height, and lung function characteristics of the 12 subjects have been published. ${ }^{\prime}$

\section{COMPUTED TOMOGRAPHY}

For the computed tomography we used an Elscint 2002 whole body scanner with a single scan time of five seconds. Data from the scanner were stored on magnetic tape and transferred to a separate viewing console for analysis. Identical protocols were used for scanning all the subjects. The subject was asked to breathe in to TLC and signal when his lungs were full. An inspiratory scan was recorded. The subject was then asked to breathe out to RV and signal when his lungs were empty. The expiratory scan was then recorded. Scans were taken in this fashion from apex to base, at TLC and RV, with constant slice intervals of $10-20 \mathrm{~mm}$.

Measurements were made in a $1 \mathrm{~cm}$ wide arc of peripheral lung tissue, centred $8 \mathrm{~mm}$ from the costal outline (fig 2) in each tomographic section. The radiographic density of vertically sequential $1 \mathrm{~cm}$ 


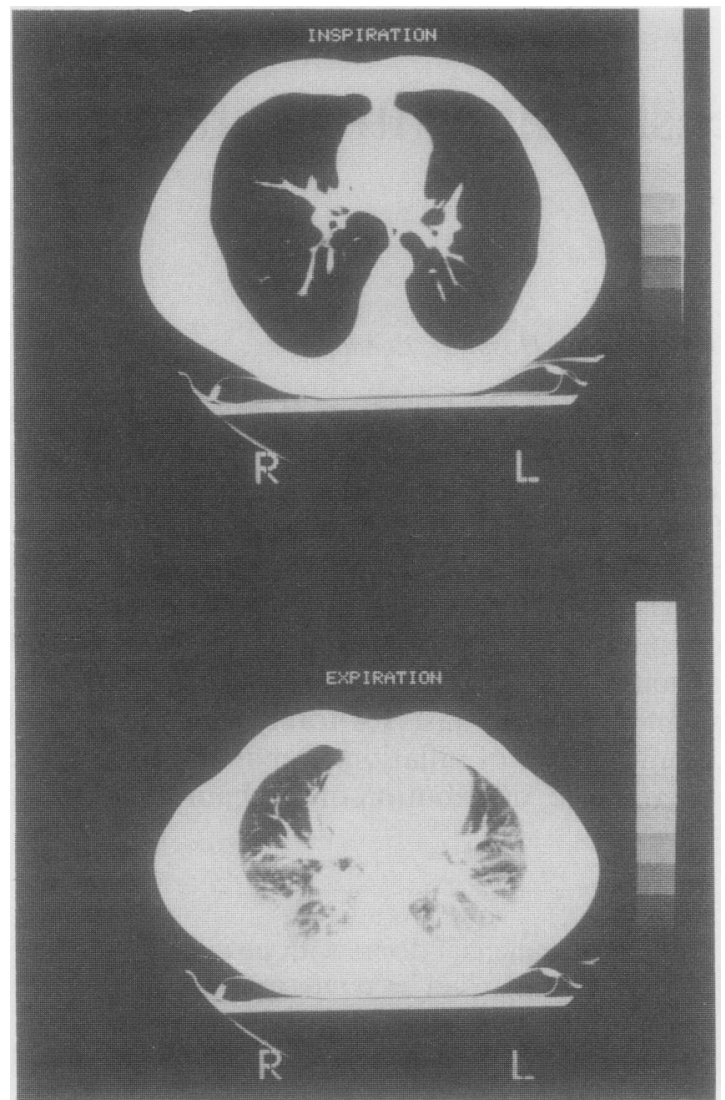

Fig 1 Computed tomogram of a supine normal subject taken at full inspiration (total lung capacity) and full expiration (residual volume) to show the difference in vertical density gradient.

squares of tissue in this arc were noted by using the area of interest subroutine, which is incorporated into the scanner software. Physical density was calculated on the assumption of a linear relation to radiographic density $(\rho=(1000$ - radiological density in Hounsfield units)/1000). This assumption has been justified experimentally in a previous study. ${ }^{1}$ So that density measurements in one tomogram could be related to those at the same hydrostatic level in another, we chose the middle of the right atrium as a horizontal reference plane. The right atrium may be seen by looking at the scan slice immediately cephalad to the diaphragm, where the atrium lies wrapped around the ventricles. Its mid height is easily determined in full inspiration and at residual volume. The densities of successive $1 \mathrm{~cm}$ thick axial planes of peripheral lung tissue were calculated by summing values from the appropriate block in each arc, the level of the mid right atrium being used as the reference plane.

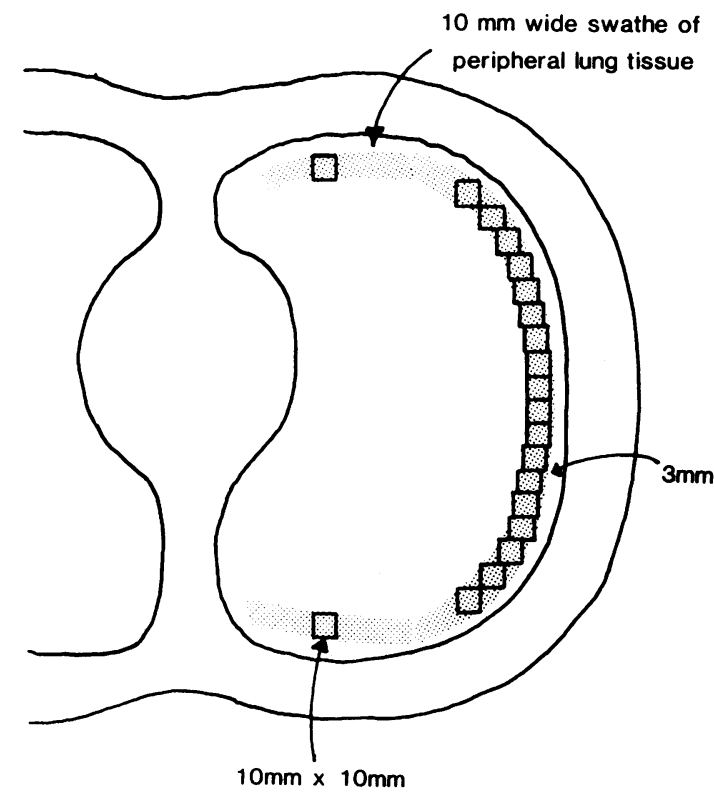

Fig 2 Pictorial display of the site of peripheral lung samples from the computed tomogram of a supine subject. The. outlined squares show the position of the density measurements used to assess the vertical gradient.

ANALYSIS

Density values for the right and left lung were compared by Student's paired $t$ test.

\section{Results}

The densities of $1 \mathrm{~cm}$ axial sections of peripheral lung tissue are shown in figure 3 and the table. At TLC the mean (SD) density of peripheral lung tissue in the reference plane was $0.0715(0.017) \mathrm{g} / \mathrm{cm}^{3}$. The vertical gradient of density was slight and almost linear. At RV the density in the reference plane was $0.272(0.067) \mathrm{g} / 乏$ $\mathrm{cm}^{3}$. The vertical density gradient was curvilinear and more pronounced. There was no significant difference between the values obtained from the right and from the left lung.

\section{THEORETICAL ANALYSIS}

A healthy adult lung at TLC has a weight of $800 \mathrm{~g}$ (and hence a lung tissue volume of $800 \mathrm{ml}$ ) and a gas capacity of $6000 \mathrm{ml}$, distended by a transpleural pressure of $30 \mathrm{~cm} \mathrm{H} \mathrm{H}_{2} \mathrm{O}$ (that is, $30 \mathrm{~g} / \mathrm{cm}^{2}$ ). When the distending pressure is reduced the volume of gas in the lung falls almost linearly, by some $200 \mathrm{ml} / \mathrm{cm} \mathrm{H}_{2} \mathrm{O}$ (that is, $0.93 \mathrm{ml} / \mathrm{ml} \mathrm{TLC} / \mathrm{g} / \mathrm{cm}^{2}$ ), until a residual volume of about $1500 \mathrm{ml}$ is reached. This description $\mathbb{D}$ refers solely to the change in gas volume, and takes no $\frac{\Omega}{\mathbb{D}}$ account of any alteration in blood or other tissue $Q$ volumes of the lung. 
Many geometric and mechanical factors contribute to the distribution of weight within the lung. For this model we assumed that the lung was like a fluid in an irregular container, in which there is a predictable vertical gradient of density modified by compressibility but no horizontal gradient, as in the case of a conical flask of water. In such a model density could be sampled along the vertical edge of the fluid, allowing us to model the properties of functionally equivalent tissue at the lung periphery by the properties of a hypothetical vertical plane.

If there were a tall, $1 \mathrm{~cm}$ square column of mechanically identical alveoli with the characteristics just described and no others, the alveoli would show a vertical gradient of size owing to the progressive increase in weight of the overlying part of the column. This may be calculated by the procedure illustrated in figure $4 a$. In such a model the column could be of

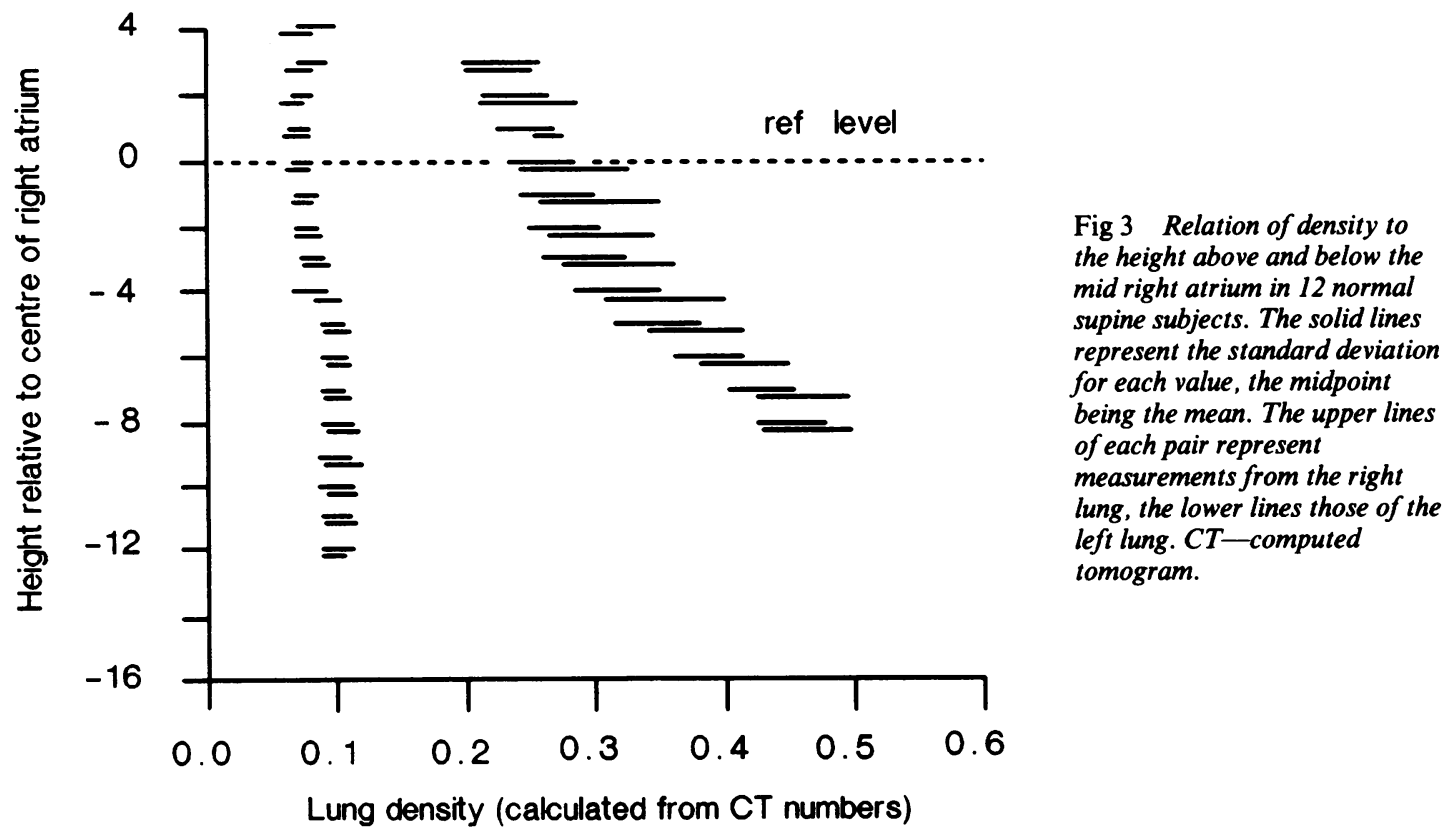

Density of cephalocaudal samples of peripheral lung tissue in 12 normal supine subjects (each sample related to the level of the mid right atrium)

\begin{tabular}{|c|c|c|c|c|c|c|c|c|}
\hline \multirow{3}{*}{$\begin{array}{l}\text { Height }(\mathrm{cm}) \text { above and } \\
\text { below mid right atrium }\end{array}$} & \multicolumn{8}{|c|}{ Mean $(S D)$ density $(\mathrm{g} / \mathrm{cm})$} \\
\hline & \multicolumn{4}{|c|}{ Inspiration } & \multicolumn{4}{|c|}{ Expiration } \\
\hline & Right & & Left & & Right & & Left & \\
\hline $\begin{array}{r}+4 \\
+3 \\
+2 \\
+1 \\
0 \\
-1 \\
-2 \\
-3 \\
-4 \\
-5 \\
-6 \\
-7 \\
-8 \\
-9 \\
-10 \\
-11 \\
-12\end{array}$ & $\begin{array}{l}0.084 \\
0.081 \\
0.074 \\
0.071 \\
0.073 \\
0.077 \\
0.077 \\
0.081 \\
0.079 \\
0.097 \\
0.098 \\
0.097 \\
0.100 \\
0.098 \\
0.098 \\
0.099 \\
0.099\end{array}$ & $\begin{array}{l}(0.029) \\
(0.022) \\
(0.015) \\
(0.015) \\
(0.016) \\
(0.017) \\
(0.018) \\
(0.018) \\
(0.027) \\
(0.019) \\
(0.019) \\
(0.018) \\
(0.023) \\
(0.022) \\
(0.024) \\
(0.025) \\
(0.022)\end{array}$ & $\begin{array}{l}0.070 \\
0.071 \\
0.066 \\
0.069 \\
0.070 \\
0.074 \\
0.077 \\
0.084 \\
0.093 \\
0.099 \\
0.102 \\
0.100 \\
0.104 \\
0.104 \\
0.103 \\
0.102 \\
0.097\end{array}$ & $\begin{array}{l}(0.023) \\
(0.020) \\
(0.018) \\
(0.018) \\
(0.017) \\
(0.016) \\
(0.019) \\
(0.019) \\
(0.020) \\
(0.020) \\
(0.018) \\
(0.019) \\
(0.025) \\
(0.028) \\
(0.023) \\
(0.024) \\
(0.019)\end{array}$ & $\begin{array}{l}0.231 \\
0.239 \\
0.247 \\
0.259 \\
0.271 \\
0.276 \\
0.292 \\
0.317 \\
0.348 \\
0.388 \\
0.428 \\
0.451\end{array}$ & $\begin{array}{l}(0.054) \\
(0.050) \\
(0.043) \\
(0.050) \\
(0.058) \\
(0.056) \\
(0.063) \\
(0.064) \\
(0.067) \\
(0.052) \\
(0.051) \\
(0.052)\end{array}$ & $\begin{array}{l}0.226 \\
0.249 \\
0.264 \\
0.285 \\
0.303 \\
0.305 \\
0.318 \\
0.355 \\
0.377 \\
0.414 \\
0.460 \\
0.463\end{array}$ & $\begin{array}{l}(0.051) \\
(0.074) \\
(0.021) \\
(0.084) \\
(0.092) \\
(0.081) \\
(0.085) \\
(0.092) \\
(0.073) \\
(0.068) \\
(0.069) \\
(0.068)\end{array}$ \\
\hline
\end{tabular}


Assume density this element $=0.0625$

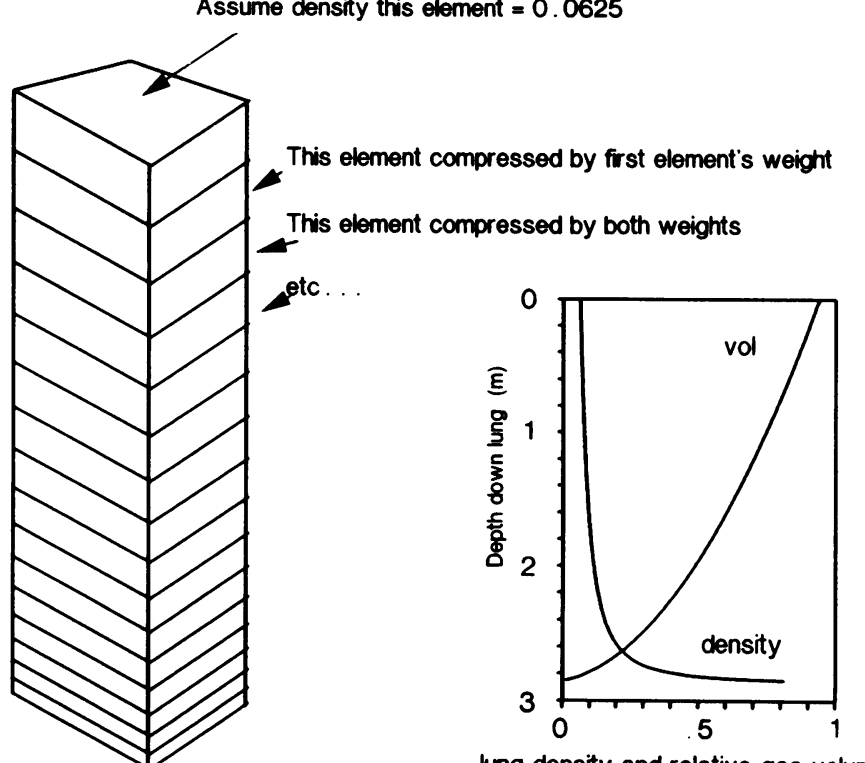

lung density and relative gas volume

Fig 4 (a) Pictorial representation of the $\stackrel{\overrightarrow{\vec{\omega}}}{\vec{\partial}}$ changes occurring in volume and pressure $\mathrm{O}$ as a result of gravity on mechanically identical alveoli in a vertical column. (b) Values of volume and density according to lung depth computed from the changes described in $(a)$.

infinite height and somewhere along its length would be a segment corresponding to any vertical element of real lung. The $1 \mathrm{~mm}$ thick element at the top of the column is presumed for convenience to be a sample of healthy lung that has been inflated to twice TLC. This would ensure we were above the top of the "real normal" lung. It will have a density of:

Normal lung weight $/(2 \times$ TLC + normal lung tissue $)$ that is, $800 /(12000+800)=0.0625 \mathrm{~g} / \mathrm{ml}$.

This $1 \mathrm{~mm}$ thick slice will exert a pressure of 0.00625 $\mathrm{g} / \mathrm{cm}^{2}$ on the element below and reduce its gas volume by $(0.03 \times 0.1 \times 0.00625)=0.0001875 \mathrm{ml}$. The density of this second element will therefore be 0.0625 / $(1-0.0001875)=0.06262$, and it and the element above will exert a combined pressure of $(0.00625+$ $0.006262)=0.012512 \mathrm{~g} / \mathrm{cm}^{2}$ on the element below. This calculation may be repeated indefinitely until the density obtained at the bottom of any "real normal" lung is exceeded. The results of the calculation are shown in figure $4 b$ in graphical form.

A column of model lung at any degree of average deflation may also be represented by an appropriate region of the curve of computed values shown in figure $4 b$. Figure 5 compares the densities obtained in real lung at TLC with the corresponding region of the curve of computed values. There is a systematic and statistically significant difference between the ob. served values of density and those obtained from the curve. This difference was attributed to the presence of blood vessels, which distended progressively as the hydrostatic pressure increased, and which were not considered in the simple hypothetical model of figure $4 b$. The characteristics of this hypothetical componen may be calculated by subtracting the values obtained from the curve from those observed. Although the observed points lie close to the predicted curve, they show slight but systematically greater changes of density with position than the curve, which are more obvious at RV than TLC. To check whether attribuz ting the differences to blood vessel distension was reasonable we took the morphometric data on the pulmonary circulation of Singhal et al, ${ }^{9}$ excluded the four largest generations of arteries and veins, whichb did not reach the lung periphery, and calculated a tota $\mathrm{B}$. vascular volume of $70 \mathrm{ml}$ in the peripheral arterial tree $70 \mathrm{ml}$ in the capillaries, and $70 \mathrm{ml}$ in the peripheraB veins, which makes a total vascular volume of $210 \mathrm{mb}$ in a lung of $6400 \mathrm{ml}$ (gas and tissue). This vascular component would contribute $210 / 6400=0.033 \mathrm{~g} / \mathrm{cm}$ t to the total density at TLC-that is, about $40 \%$. Inspection of figure 5 shows that the values of densityo at TLC (left hand set of points) are less than the computed values, shown by the curve, at the uppen part of the curve by up to $0.012 \mathrm{~g} / \mathrm{cm}^{3}$ and exceed them by up to $0.012 \mathrm{~g} / \mathrm{cm}^{3}$ at the lower part, implying as twofold variation in vascular volume over the $16 \mathrm{~cm}$ range from the top to the bottom of the supine lung. A residual volume, when average density rises almosit fourfold to $0.323 \mathrm{~g} / \mathrm{cm}^{3}$, this effect would be greaterapproximately in proportion to the local increase in density - so would be considerably more obvious at⿱艹 the lower than at the upper part of the lung. This is exactly what is shown in the right hand set of points in figure 5 . 


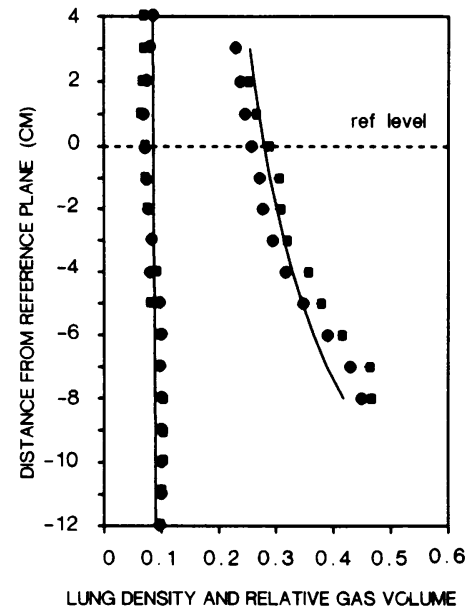

Fig 5 Mean values of density at total lung capacity (left) and at residual volume (right). Circles represent right lungs and squares left lungs. The solid lines represent appropriate parts of the curve shown in fig $4 b$, calculated as described in the text.

\section{Discussion}

These results suggest that the density gradients seen in computed tomography of the lungs and the differences in such gradients at different degrees of inflation relate to mechanical properties of the lungs. The validity of these findings rests on the ability of computed tomography to measure local tissue weight and volume. Computed tomography pixel values have been shown to provide accurate estimates of density and position in several studies, ${ }^{10-12}$ including our own on the lung, ${ }^{1}$ which used the same scanner and the same group of subjects as the present work.

The density of the lung at different degrees of inflation has been measured previously but the curvilinear relationship has not been commented on. ${ }^{3}$ Several authors have drawn attention to the vertical density gradient as seen in $\operatorname{man}^{3}$ and in the dog. ${ }^{1314}$ Some have expressed it in terms of radiographic density. ${ }^{3-715}$ There is much physiological and histological evidence for a systematic change in alveolar size with vertical position in the lung ${ }^{16-20}$ and equally abundant evidence for variation in large and small vessel calibre with hydrostatic site. ${ }^{21}{ }^{22}$ More recently, Rhodes et al ${ }^{23}$ and Brudin et al $^{24}$ have shown the vascular component to be the major contributor to vertical density gradients in lung tissue.

The present findings support the view that the normal lung may be treated as if it were a compressible foam with the compliance of healthy adult lung tissue, permeated by vessels that impose an additional and greater density gradient, the characteristics of which are maintained with the change from total lung capacity to residual volume. This implies that computed tomography can be used to provide an index of local mechanical properties of lung tissue.

This elementary model appears to ignore the fact that the whole lung pressure-volume curve is curvilinear. Other complex mechanical forces, such as the presence of more than one curved pleural surface and local irregularities induced by the closing volume, are also ignored. It does, however, predict the distribution of density at various degrees of inflation and deflation in a way that allows variations from normal to be diagnosed with confidence.

Because the vertical gradients of radiographic density shown by computed tomography of the lungs are partly masked by radial density gradients due to the bronchial and vascular trees, we made measurements only in peripheral lung regions. Differences between central and peripheral distribution of density in computed tomograms have been noted previously in models of diseased lungs. Hedlund et $a l^{25}$ found that hydrostatic pulmonary oedema induced experimentally in dogs by inflating a balloon in the left atrium caused fluid accumulation that was central rather than peripheral and dependent rather than non-dependent. In contrast, permeability oedema of the lung, induced by oleic acid injury, was peripheral and haphazard. Furthermore, Vock and Salzman ${ }^{26}$ found a significant correlation between non-dependent lung density and pulmonary arterial pressure in 33 patients with chronic heart disease. This diversion of blood into the upper part of the lung in supine subjects will complicate the analysis of vertical gradients of density in diseased lungs compared with normal lungs.

\section{References}

1 Denison DM, Morgan MDL, Millar AB. Estimation of regional gas and tissue volumes of the lung in supine man using computed tomography Thorax 1986; 41:620-8.

2 Millar AB, Fromson B, Strickland B, Denison DM. Computed tomography based estimates of regional gas and tissue volume of the lung in supine subjects with chronic airflow limitation or fibrosing alveolitis. Thorax 1986;41:932-9.

3 Robinson PJ, Kreel L. Pulmonary tissue attenuation with computed tomography: comparison of inspiration and expiration scan. J Comput Assist Tomogr 1979;3:740-8.

4 Hedlund LW, Vock P, Effman EL. Computed tomography of the lung: densitometric studies. Radiol Clin North Am 1983;21:775-88.

5 Kreel L. Computed tomography of the thorax. Radiol Clin North Am 1978;16:575-84.

6 Dohring W. Quantitative analyses of regional pulmonary ventilation using Compton densitometry and computed tomography. Prog Respir Res 1979;11:48-75.

7 Rosenblum LJ, Mauceri RA, Wallenstein DE, et al. Density patterns in the normal lung as determined by 
computed tomography. Radiology 1980;137:409-16.

8 Murray J. The normal lung. Philadelphia: Saunders, 1976:86-8.

9 Singhal S., Henderson R, Horsfield K, Harding K, Cumming G. Morphometry of the human pulmonary arterial tree. Circ Res 1973;33:190-7.

10 Mull RT. Mass estimates by computed tomography: physical density from CT numbers. AJR 1984; 143:1101-4.

11 Huang HK, Wu SC. The evaluation of mass densities of the human body in vivo from CT scans. Comput Biol Med 1976;6:337-43.

12 Hedlund L, Friedman E, Bates M, et al. A comparison of lung density measured gravimetrically and by computed tomography [abstract]. Invest Radiol 1982;17:S11.

13 Hoffman EA. Effect of body orientation on regional lung expansions: a computed tomographic approach. J Appl Physiol 1985;59:468-80.

14 Wandtke JC, Hyde RW, Fahey PJ, et al. Measurement of lung gas volume and regional density by computed tomography in dogs. Invest Radiol 1986;21:108-17.

15 Wegener OH, Koeppe P, Oeser H. Measurement of lung density by computed tomography. J Comput Assist Tomogr 1978;2:263-72.

16 Kaneko K, Milic-Emili J, Dolovich MB, Dawson A, Bates DV. Regional distribution of ventilation and perfusion as a function of body position. J Appl Physiol 1966;21:767-77.

17 Hogg JC, Nepszy S. Regional lung volume and pleural pressure gradient estimated from lung density in dogs.
J Appl Physiol 1969;27:198-203.

18 Glazier JB, Hughes JMB, Malone JE, West JB. Vertical $\vec{\Rightarrow}$ gradient of alveolar size in lung of dogs frozen intact. J Appl Physiol 1967;23:694-705.

19 Michels DB, West JB. Distribution of pulmonary ventilation and perfusion during short periods of weightless- $\frac{\bar{\sigma}}{\bar{\rho}}$ ness. J Appl Physiol: Respirat Environ Exercise Physiol $\mathbb{ه}$ 1978;45:987-98.

20 West JB. Regional differences in the lung. New York: के Academic Press, 1979:33-319.

21 Howell J, Permutt S, Proctor D, Riley R. Effect of inflation of the lung on different parts of pulmonary $\vec{\omega}$ vascular bed. J Appl Physiol 1961;16:71-6.

22 Permutt S, Howell J, Proctor D, Riley R. Effect of lung inflation on static pressure-volume characteristics of pulmonary vessels. J Appl Physiol 1961;16:64-70.

23 Rhodes CG, Wollmer P, Fazio F, Jones T. Quantitative measurements of regional extravascular lung density $\stackrel{p}{o}$ using positron emission and transmission tomography. J Comput Assist Tomogr 1981;5:783-91.

24 Brudin LH, Rhodes CG, Valind SO, Wollmer P, Hughes

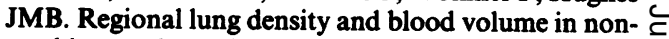
smoking and smoking subjects measured by PET. J Appl Physiol 1987;63:1324-34.

25 Hedlund LW, Vock P, Effman EL, Lischko MM, Putman CE. Hydrostatic pulmonary oedema: an analysis of lung density changes by computed tomography. Invest Radiol 1984;19:254-62.

26 Vock P, Salzmann C. Comparison of computed tomographic lung density with haemodynamic data of the pulmonary circulation. Clin Radiol 1986;37:459-64. 